\title{
Functions of decision support systems (JRodos as an example): overview and new features and products
}

\author{
W. Raskob, C. Landman and D. Trybushnyi \\ Karlsruhe Institute of Technology (KIT), Hermann-von-Helmholtz-Platz 1, 76344 Eggenstein-Leopoldshafen, Germany.
}

\begin{abstract}
Under the auspices of its Euratom Research Framework Programmes, the European Commission (EC) has supported the development of the RODOS (Real-time Online DecisiOn Support) system for off-site emergency management after nuclear accidents for more than a decade. Significant additional funds have been provided by many national research programmes, research institutes and industrial collaborators. In particular, the German Ministry of the Environment, Nature Conservation and Reactor Safety financially contributed to the project with an emphasis on early emergency response. The final result of these collaborative actions, the comprehensive RODOS system, can be applied generally within and across Europe. It can be used in national or regional nuclear emergency centres, provides coherent support at all stages of an accident, and includes the long-term management and restoration of contaminated areas. Within the NERIS-TP project, several model improvements have been developed, covering the worldwide applicability of the system, the coupling with the early notification system of the IAEA, improved countermeasure modelling and model adaptation for the new ICRP 103 recommendations. Several of these new tools were also integrated into the ARGOS system (Hoe S., Müller H., Gering F., Thykier-Nielsen S., Havskov Sorensen J. (2002) ARGOS 2001: A decision support system for nuclear emergencies. In: American Nuclear Society Transactions. Winter Meeting Vol. 87, pp. 574-579).
\end{abstract}

Keywords: RODOS / model improvements / worldwide applicability / countermeasure modelling / ARGOS

\section{Introduction}

The RODOS project was launched in 1989 and increased in size through the European Commission's Framework Programmes. Many national research and development programmes, research institutions and industrial collaborators have provided significant additional funds. Up to 40 institutes from some 20 countries in Europe and the former Soviet Union were actively involved in the project.

\section{Strategic achievements}

The comprehensive decision support system RODOS has been developed for application within and across Europe (Ehrhardt and Weis, 2000). It can be used in national or regional nuclear emergency centres for providing coherent support at all stages of an accident; that is, before, during and after a release, including the long-term management and restoration of contaminated urban and agricultural areas. The system can support decisions about the introduction of a wide range of potentially useful countermeasures, such as sheltering and evacuation of people, distribution of iodine tablets, food restrictions, agricultural countermeasures, relocation, decontamination, restoration, etc., that aim at mitigating the consequences of an accident with respect to health, the environment and the economy. RODOS is applicable for accidental releases into the atmosphere and into various aquatic environments. Appropriate interfaces exist for the coupling to local and national radiological monitoring data, meteorological measurements and numerical weather forecast systems, and for the adaptation of the databases to local, regional and national conditions in Europe.

\section{Technical performance}

\subsection{Concept of decision support}

The RODOS system provides coherent and detailed information for supporting decisions at all levels, ranging from descriptive reports, such as maps of contamination patterns and dose distributions predicted by model calculation or measurements, if available, to a detailed evaluation of the benefits and disadvantages of various countermeasure strategies and their ranking according to the societal preferences as perceived by the decision-makers. It is also able to perform 'what-if' calculations, allowing investigations of how a situation could develop in different scenarios. The user interface provides access to models, data and system parameters, in a hierarchical structure with a degree of detail adapted to the needs and qualification of users, whereby different user groups determine 


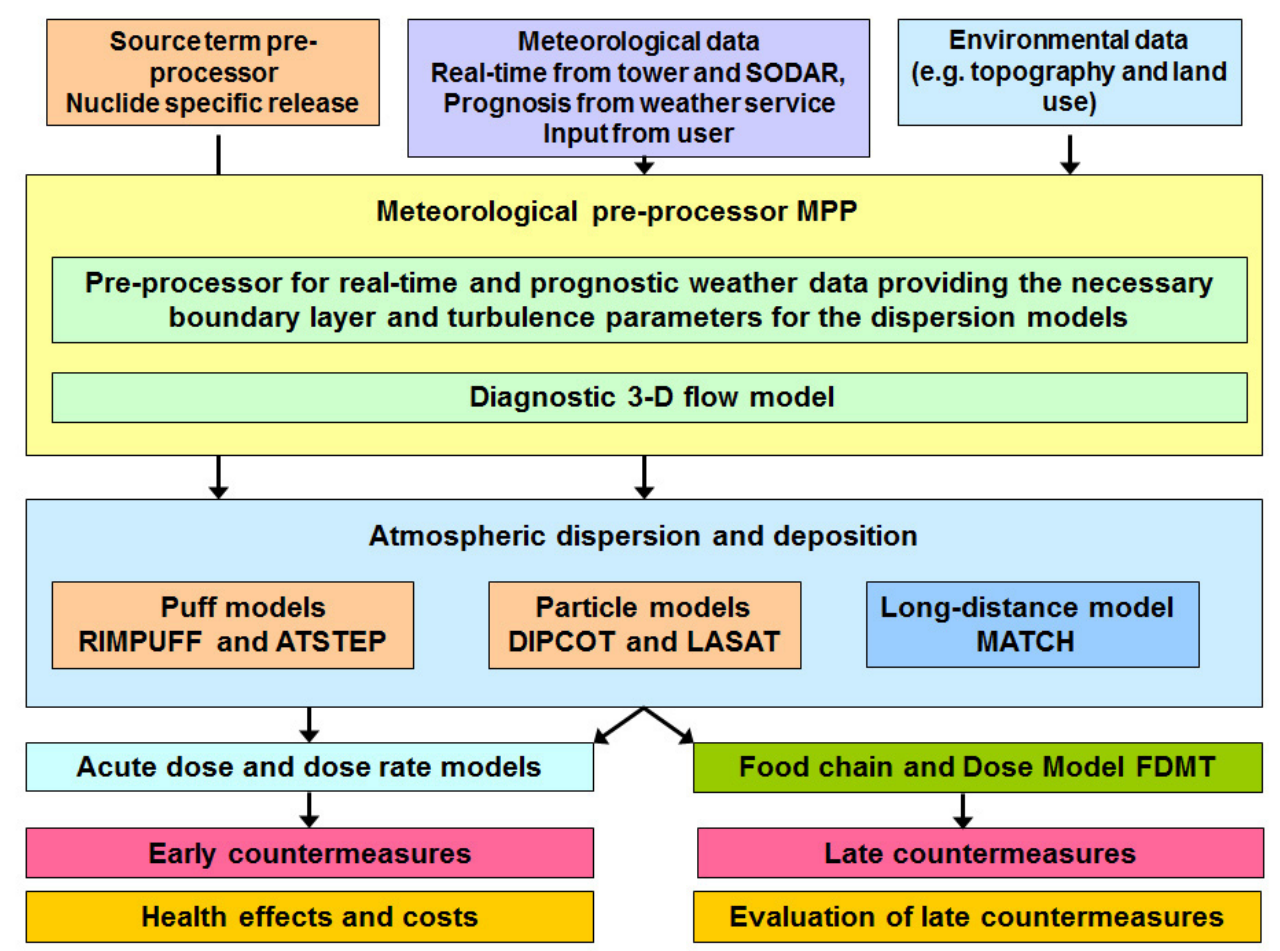

Figure 1. Simulation models in RODOS.

the access rights and thus the possible depth of the access. At the lowest level the user interface offers an easy-to-understand appearance but grants only limited access to the various input aspects; at the highest level, the full spectrum of the system's menus and tools is available.

\subsection{Simulation models}

The RODOS system provides suitable interfaces to meteorological and radiological monitoring data and to numerical weather prognoses from national weather services broadly used in Europe. Customisation guidelines help the user in adapting the system to regional and national conditions.

Figure 1 shows an overview of the models applicable in case of a release to the atmosphere. In addition, RODOS also contains an aquatic model chain that is described in some detail in (Raskob and Hugon, 2010).

A detailed model description can be found on the RODOS web page ${ }^{1}$ and in (Raskob and Hugon, 2010); therefore, detailed references will not be given here. In brief, one can describe the content of Figure 1 with the following. A source term pre-processor provides the necessary source term information for the atmospheric dispersion models for each time step of the simulation. A meteorological preprocessor provides the necessary meteorological input to the atmospheric dispersion models, comprising information about the status of the boundary layer and a 3-dimensional wind field that define the flow in the area of interest. In addition, information about rain patterns is given, too.

\footnotetext{
1 http://www.rodos.fzk.de
}

There are several models for atmospheric dispersion and deposition available in the distance range up to $100 \mathrm{~km}$. This includes the Gaussian puff models ATSTEP and RIMPUFF, and the particle models DIPCOT and LASAT. For longer-range calculations the Eulerian model MATCH is used. The transfer of radionuclides to terrestrial foodstuffs and the resulting radiation exposure are modelled in the Terrestrial Food Chain and Dose Model, FDMT. Countermeasure modelling is subdivided into early-phase and late-phase models.

Finally, the MAV/UT-based software package, WebHipre, has been integrated into RODOS to enable users to compare and evaluate the benefits and drawbacks of different countermeasure strategies (e.g., risks, costs, feasibility, public acceptance, perceptions, social, psychological and political implications, and preferences or value concepts of decision-makers, etc.).

\section{Improvements in NERIS-TP}

Within the NERIS-TP project (2011-2014), gaps identified after the EURANOS activities were addressed. The following topics relate to the further development of RODOS:

- improving the early- and late-phase countermeasure models EMERSIM and ARGOS-EC (both for screening), ERMIN (inhabited areas) and AgriCP (agricultural production) for the new ICRP approach for emergency and existing situations;

- coupling an emergency information system with RODOS by developing a meteorological model chain that provides meteorological data for the assessments from freely available worldwide data. 
Related to the improvements of the countermeasure models for the new ICRP recommendations, a so-called "screening model" has been developed. The screening model takes into account all terrestrial exposure pathways, including ingestion, and considers sheltering, evacuation, relocation, food restrictions and the use of iodine tablets for thyroid blocking, for reducing or avoiding doses. The screening goal is the identification of action strategies that limit the total effective equivalent dose received from all pathways over a given time period, the "criterion dose", below a given reference revel.

In the later phase, the decontamination of inhabited areas plays an important role. Within EURANOS, the European model for inhabited areas (ERMIN) was developed for that purpose. However, due to the complexity of the situation, ERMIN required further improvement in its handling. The most important work was the development and implementation of a wizard that supports the user in defining an appropriate decontamination strategy. This was achieved by an iterative calculation process in which ERMIN defines those surfaces that contribute most to the dose to the population. In this way, the user can revise the strategy by selecting countermeasures appropriate for that particular surface. The selection process is supported by the wizard in proposing possible countermeasures. This selection process will finally result in a more sensible countermeasure strategy.

The countermeasure model for food production systems AgriCP has been further stabilised and a pre-processor developed, allowing one to start the model with monitoring information. Monitoring information can comprise, among others, activity concentrations and dose rates.

The coupling with the early notification system of the IAEA, USIE ${ }^{2}$, was carried out by extracting source term and location information, if available. To ensure that weather data will be available at any possible location, a modelling system has been developed using freely available meteorological global data from the NOMADS (National Operational Model Archive \& Distribution System) servers of the NOAA (National Oceanic and Atmospheric Administration) from the US and scaling them down to local conditions with the WRF model (Skamarock et al., 2008). This model chain development was mainly important for RODOS, as ARGOS has used the NOMADS data for a long time. Therefore, the technical realisation was limited to the RODOS system.

\section{Conclusions}

The decision support systems RODOS and ARGOS have been improved with components which were lacking following the EURANOS project. This comprised, in particular, new international recommendations and modelling improvements for the later-phase modules. Further to this, the worldwide applicability of the systems has been strengthened. However, the Fukushima incident has highlighted further gaps which will be tackled in the still ongoing European research project PREPARE $^{3}$.

\section{References}

Ehrhardt J., Weis A. (Eds.) (2000) RODOS: Decision Support System for Off-site Nuclear Emergency Management in Europe. European Commission, Brussels, Report EUR 19144.

Hoe S., Müller H., Gering F., Thykier-Nielsen S., Havskov Sorensen J. (2002) ARGOS 2001: A decision support system for nuclear emergencies. In: American Nuclear Society Transactions. Winter Meeting Vol. 87, pp. 574-579.

ICRP Publication 103 (2007) The 2007 Recommendations of the International Commission on Radiological Protection, Ann. ICRP 37 (2-4).

Raskob W., Hugon M. (Eds.) (2010) Enhancing nuclear and radiological emergency management and rehabilitation: Key Results of the EURANOS European Project, Radioprotection 45 (5), Supplément 2010.

Skamarock W.C., Klemp J.B., Dudhia J., Gill D.O., Barker D.M.,Duda M.G., Huang X.-Y., Wang W., Powers J.G. (2008) A Description of the Advanced Research WRF Version 3.

Cite this article as: W. Raskob, C. Landman, D. Trybushnyi. Functions of decision support systems (JRodos as an example): overview and new features and products. Radioprotection 51(HS1), S9-S11 (2016). 